\title{
LEGITIMIDADE E GOVERNABILIDADE NA REGULAÇÃO DO SISTEMA FINANCEIRO
}

\author{
Ademir Antonio Pereira Júnior ${ }^{1}$ \\ LEGITIMACY AND GOVERNABILITY IN FINANCIAL REGULATION
}

\section{RESUMO}

A RELAÇÃO ENTRE DIREITO E ECONOMIA PODE RESULTAR NUMA OPOSIÇÃO ENTRE GOVERNABILIDADE E LEGITIMIDADE LEGALRACIONAL, UMA VEZ QUE SE BASEIAM EM DIFERENTES RACIONALIDADES. A REVISÃO JUDICIAL DA REGULAÇ̃̃O DO SISTEMA FINANCEIRO EVIDENCIA ESSE CONFLITO, OBSERVADO NESTE TRABALHO SOB A PERSPECTIVA DA JURISPRUDÊNCIA CONStitucional do Supremo Tribunal Federal (STF). 0 OBJETIVO DESTE TRABALHO RESUME-SE ENTÃO EM IDENTIFICAR O CONFLITO ENTRE GOVERNABILIDADE E A EXIGÊNCIA DE LEGITIMIDADE LEGAL DAS DECISÕES ANALISADAS PELA CORTE NO QUE CONCERNE À REGULAÇÃO FINANCEIRA. O ESTUDO DE CASOS EVIDENCIA QUE O STF TEM REJEITADO ARGUMENTOS ECONÔMICOS, ENTRETANTO, TEM PRESERVADO A LÓGICA DA GOVERNABILIDADE COM DECISŌES CONTRADITÓRIAS E INCOERENTES PAUTADAS EM ARGUMENTOS FORMAIS. DESSA FORMA, POSSÍVEL IDENTIFICAR O PAPEL INSTITUCIONAL CONFERIDO PELO STF À CONSTITUIÇÃO FEDERAL DE 1988, CONSIDERANDO O CONTEXTO DAS CRISES ECONÔMICAS VIVIDAS PELO BRASIL A PARTIR DA METADE DA DÉCADA DE 1980 E SUA NOVA CONFORMACĀO A PARTIR DA Emenda Constitucional n. 40.

\section{PALAVRAS-CHAVE}

REGULAÇÃO FINANCEIRA; JURISPRUDÊNCIA CONSTITUCIONAL; CRISE FINANCEIRA; GOVERNABILIDADE; LEGITIMIDADE

\section{ABSTRACT}

THE RELATION BETWEEN LAW AND ECONOMICS MIGHT RESULT IN AN OPPOSITION BETWEEN GOVERNABILITY AND LEGALRATIONAL LEGITIMACY, SINCE THEY ARE BASED IN DIFFERENT RATIONALITIES. JUDICIAL REVIEW OF FINANCIAL REGULATION SHOWS THAT COFLICT, WHICH IS HERE ANALYSED FROM THE VIEWPOINT OF THE CONSTITUTIONAL JURISPRUDENCE OF THE Brazilian Supreme Court (SUPREMo Tribunal FEDERAL - STFI. IN BRIEF, THE PURPOSE OF THIS ARTICLE IS TO IDENTIFY THE OPPOSTION BETWEEN GOVERNABILITY AND THE NEED FOR LEGAL-LEGITIMACY IN THE CASES ANALYSED BY THE COURT CONCERNING FINANCIAL REGULATION. THE CASE STUDIES SHOW THAT THE JUDICIAL REVIEW BY STF HAS REJECTED ECONOMIC ASPECTS OF THE CASE, HOWEVER IT HAS PRESERVED GOVERNABILITY RATIONALITY WITH INCOHERENT AND CONTRADICTORY DECISIONS BASED ON FORMAL ARGUMENTS. THEREBY, IT IS POSSIBLE TO IDENTIFY THE INSTITUTIONAL ROLE GRANTED BY STF TO THE BRAZILIAN CONSTITUTION DATED FROM 1988, CONSIDERING THE CONTEXT OF ECONOMIC CRISIS EXPERIMENTED BY BRAZIL IN THE 80'S AND THE 40TH AMEDMENT.

\section{KEYWORDS}

FINANCIAL REGULATION; CONSTITUTIONAL JURISPRUDENCE; FINANCIAL CRISIS; GOVERNABILITY; LEGITIMACY

\section{Direito, eCONOMia E ORDEM DEMOCRÁtica}

Uma caricatura dos requisitos e objetivos do pensamento jurídico e do pensamento econômico leva a um posicionamento antagônico dessas duas racionalidades. De um lado, o pensamento jurídico condiciona a ação humana a partir da imposição de premissas e 
princípios, que, uma vez estabelecidos, devem ser obedecidos como condição à calculabilidade e previsibilidade necessárias à perpetuação de uma estrutura racional de poder contida no seio da sociedade. Opondo-se então ao raciocínio baseado em premissas e princípios, encontra-se o raciocínio econômico, que exige da ação a busca por resultados, ou seja, propõe como limite e objetivo à atuação humana a procura por eficiência, consubstanciada em resultados que se alcançariam independentemente das condições e premissas estabelecidas, cambiáveis de acordo com a conjuntura, prevalecendo, assim, a preocupação com os fins em detrimento dos meios empregados.

A despeito do exagero intrínseco a uma caricatura, essa oposição pode ser verificada em larga medida na relação entre essas diferentes estruturas de decisão, principalmente quando as circunstâncias conjunturais subvertem as condições de decisão e exigem uma atuação célere e efetiva mesmo sob pena de desrespeito às premissas formais estabelecidas pelo direito, resultando na polarização entre eficiência econômica e certeza jurídica. ${ }^{2}$

O Poder Judiciário apresenta como uma de suas mais importantes funções institucionais garantir a calculabilidade e previsibilidade do direito, mediante a preservação das premissas e princípios jurídicos, constituindo assim o lócus, por essência, de preservação da legalidade e prevalência do raciocínio jurídico. Ao contrário, o sistema financeiro de um país, que tem em seu núcleo as questões da moeda e do crédito, consiste num ilustrativo exemplo de setor composto e pressionado por decisões eminentemente econômicas, que por seu grau muitas vezes elevado de complexidade e especificidade técnica, terminam por se postar atrás de uma blindagem técnica, capaz de submeter aqueles pouco versados na ciência econômica a um elevado grau de ignorância e distanciamento de seu conteúdo e significado. Dessa forma, possível afirmar que, enquanto o Poder Judiciário constitui o lócus por essência do raciocínio jurídico, o sistema financeiro é o lócus por excelência do raciocínio econômico. O encontro de ambos em uma disputa judicial envolvendo matéria pertinente ao sistema financeiro evidencia essa oposição, que passa, neste momento, a ser o objeto de discussão deste trabalho, que propõe analisar a atuação do Supremo Tribunal Federal (STF) na apreciação das políticas estatais no âmbito da regulação do Sistema Financeiro Nacional.

A justificativa dessa proposta temática encontra-se em duas razões distintas, que, no entanto, se comunicam. A primeira delas consiste na relevância das atividades desenvolvidas pelo sistema financeiro, que determina o fluxo monetário e a disponibilidade de crédito na sociedade, influenciando seu poder de compra e capacidade de investimento, o que tem conseqüências imediatas sobre o desenvolvimento econômico do País. Esse papel apresentava ainda maior relevo quando da abertura democrática no Brasil, em meados da década de 1980, época em que o País se encontrava inserido em contexto de hiperinflação, acompanhado pela desestabilização do padrão monetário e das finanças públicas, que se tornavam 
incapazes de financiar, como há muito se fazia no Brasil, as atividades produtivas, desorganizando assim o sistema produtivo. Em outras palavras, o Brasil, ao mesmo tempo em que se libertava do regime autoritário imposto pelos militares, vivia uma crise econômica gravíssima com potencial para avançar no sentido de uma crise social, cujo núcleo se encontrava no coração do sistema financeiro: a moeda e o crédito.

Em função da relevância desse setor para o desenvolvimento econômico do País, o diálogo entre racionalidade econômica e jurídica consubstanciado na apreciação de medidas pertinentes ao sistema financeiro pela corte constitucional brasileira é capaz de evidenciar o desenvolvimento institucional da Constituição Federal de 1988, originada em um contexto de crise econômica, que colocava sua efetividade à prova. A nova lei máxima do País deveria ser capaz de institucionalizar a transição democrática brasileira, restabelecendo o império da lei, e ao mesmo tempo conviver com a lógica econômica da eficiência e dos resultados, despreocupada com a qualificação dos procedimentos e meios utilizados nas ações estatais voltadas à estabilização da moeda e da balança de pagamentos do país, o que dependia em larga medida da regulação econômica das atividades desempenhadas pelo Sistema Financeiro Nacional.

Portanto, o segundo motivo que justifica a escolha do tema deste trabalho diz respeito à tensão existente entre a necessidade de limitar e superar a crise econômica sofrida pelo País tendo em vista os anseios de desenvolvimento econômico, que resultou em uma atuação concentrada pelo Poder Executivo, mediante medidas céleres, eficazes e muitas vezes drásticas, que obedeciam a uma lógica de governabilidade, em face da exigência de que essas medidas fossem legítimas a partir da perspectiva jurídica, ou seja, que respeitassem as regras estabelecidas pelo direito. Essa tensão entre governabilidade e legitimação legal-racional das medidas adotadas pelo Estado brasileiro no âmbito do Sistema Financeiro Nacional impunham à nova Constituição Federal uma difícil definição: que papel ela, como marco do novo ordenamento jurídico do País, representaria.

Apresentavam-se como caminhos distintos o papel de um mero instrumento de poder à mercê das decisões econômicas, relativizada segundo os interesses e conveniências exploradas na amplitude do processo interpretativo, ou a função de limite e direcionamento da ação pública. ${ }^{3}$ Em síntese, o tema proposto permite compreender o papel institucional conferido pelo STF à Constituição Federal de 1988 e, mais amplamente, ao raciocínio jurídico, em face das demandas econômicas e sua lógica pautada por resultados.

O trabalho encontra-se então dividido nesta breve introdução, que será seguida por um capítulo que propõe evidenciar a pesquisa jurisprudencial realizada e os recortes propostos ao tema. Na seqüência, os capítulos 3 e 4 discutem as decisões do STF analisadas durante minha pesquisa, o primeiro deles apresentando decisões 
tomadas pelo STF em tempos de crise no Sistema Financeiro Nacional e na economia do País como um todo, e o segundo tratando da reformulação da disciplina constitucional do Sistema Financeiro Nacional. Por fim, a conclusão do artigo representa o capítulo 5 .

\section{Materiais e MÉtodos UTILizados NA PESQUisA}

O trabalho aqui apresentado encontra sua origem em monografia realizada no âmbito da Escola de Formação da Sociedade Brasileira de Direito Público, que pretendia definir o papel assumido pelo STF na regulação do Sistema Financeiro Nacional, partindo-se da hipótese de que existe certa deferência do STF às decisões do Poder Executivo, o que se verificaria pela constante confirmação pelo Tribunal das decisões do Poder Executivo. ${ }^{4}$

A pesquisa realizada para a redação dessa monografia evidenciou uma série de interessantes questões presentes na análise pelo STF de matérias relativas ao Sistema Financeiro Nacional, principalmente quanto à relação conflitiva entre o raciocínio jurídico e o econômico. Portanto, este artigo constitui um desdobramento da pesquisa jurisprudencial realizada naquela ocasião. A despeito da diferença de propósitos entre ambos os trabalhos, o universo de decisões pesquisadas mantém-se, uma vez que este trabalho também considera todas as ações diretas de inconstitucionalidade julgadas pelo STF que consideravam dispositivo normativo proferido pelo Estado brasileiro para regulamentar o Sistema Financeiro Nacional. Essa escolha encontra justificativa em minha intenção de evidenciar a tensão entre racionalidades existente entre a lógica econômica e jurídica, entre governabilidade e legitimidade legal-racional. A análise unicamente de ações diretas de inconstitucionalidade permite um exame mais preciso e objetivo, em que, além de não existirem peculiaridades do caso concreto a serem consideradas, a apreciação do tribunal objetiva verificar o dispositivo normativo questionado. O recorte temporal definido restringe a análise a casos cujo controle de constitucionalidade ocorre em face da Constituição Federal de 1988, uma vez que a proposta deste trabalho é observar o desenvolvimento institucional dessa Constituição.

A partir da definição desses recortes, os acórdãos foram selecionados a partir de uma busca no sítio eletrônico do STF, realizada por meio da ferramenta de busca de jurisprudência. Nessa pesquisa foram utilizados os vocábulos "sistema", "financeiro" e "habitação", combinados e relacionados por meio das ferramentas disponibilizadas pelo sítio eletrônico na forma que segue: "sistema prox 1 financeiro nao habitação". 5 Dessa busca resultou a exposição de 246 acórdãos para aquela combinação de palavras. Desses acórdãos, apenas treze consubstanciavam julgamento de ação direta de inconstitucionalidade, das quais cinco foram excluídas da análise por não se relacionarem com o tema proposto. ${ }^{6}$ 


\section{TEMPOS DE CRISE: LEGITIMIDADE LEGAL E GOVERNABILIDADE}

Direito e governabilidade não são, em princípio, antagônicos. Entretanto, a lógica da governabilidade, ligada à capacidade de uma estrutura de poder de implementar efetivamente planos e programas em face das demandas sociais e econômicas presentes no meio governado, pode, em situações extremas que exigem medidas céleres, drásticas e eficazes para a manutenção da estrutura organizacional e de poder, posicionar-se em pólo oposto ao direito. Isso porque as circunstâncias conjunturais podem demandar medidas a curto prazo que não se coadunam com a estrutura decisória estabelecida aprioristicamente pelo direito, construído com vistas à vida da sociedade no longo prazo e não um momento específico e excepcional de seu desenvolvimento. Portanto, alterações relevantes nas condições de desenvolvimento de uma sociedade podem transformar os instrumentos jurídicos estabelecidos com o intuito de certeza em obstáculos à superação da situação de crise vivenciada.

Essa tensão é largamente reconhecida nos ordenamentos constitucionais, que costumam prever, em situações de grave crise social, a decretação do estado de sítio. Essa medida implica a limitação de uma série de direitos constitucionais para a superação da crise social vivenciada. Portanto, o estado de sítio é uma medida limitativa da ordem constitucional, mas que objetiva garantir a restauração ou manutenção dessa mesma ordem constitucional. Trata-se de um reconhecimento pelo direito das peculiaridades de uma situação de crise, que exige um direito diverso daquele construído na normalidade para sua superação e posterior restauração da ordem jurídica anterior. ${ }^{7}$ As crises econômico-financeiras têm desafiado os governos por todo o mundo, e por sua intensidade ameaçam se transformar em crises sociais em escala indesejável. Essas crises também podem exigir para sua solução que o direito se adapte às contingências apresentadas, contribuindo então para o fim da crise. Nesse sentido, possível debater a necessidade da criação de um estado de sítio econômico para a garantia da estabilidade do regime. ${ }^{8}$

A não-existência dessa hipótese em nosso ordenamento jurídico leva à observação da oposição entre governabilidade e legitimidade legal-racional das decisões e medidas adotadas pelas autoridades estatais brasileiras para a regulação do Sistema Financeiro Nacional no contexto de redemocratização do País, a partir de meados da década de 1980, e o período que lhe seguiu. Isso porque o País enfrentava uma hiperinflação, acompanhada pela desestabilização do padrão monetário, das finanças públicas e do setor produtivo, o que tornava árduo o nascimento de um padrão decisório democrático no governo brasileiro e a fixação de um plano de desenvolvimento econômico para a nação, já que a preservação da governabilidade demandava medidas céleres, drásticas e a curto prazo. Nesse contexto, a Constituição Federal de 1988 representava o surgimento de uma nova ordem jurídica, que deveria garantir a transição para a democracia e consolidá-la, estabelecendo as regras do jogo democrático e garantindo o império da legalidade. Entretanto, apenas sete dias após a 
promulgação da Constituição Federal uma ação direta de inconstitucionalidade colocava a nova Constituição à prova. Trata-se da ADI n. 4-7.

\section{I ADI N. 4-7: O RACIOCÍNIO DOGMÁTICO-FORMAL EM PROL DA GOVERNABILIDADE}

Apenas sete dias após a promulgação da Constituição Federal, em 05.10.1988, o Partido Democrático Trabalhista (PDT) ingressou com uma ação direta de inconstitucionalidade perante o STF para questionar ato do Presidente da República (ADI n. 4-7), publicado no Diário Oficial da União em 07.10.1988, que aprovou o Parecer SR70 da Consultoria Geral da República. A controvérsia se estabeleceu porque o ato do Presidente da República, consubstanciado no Parecer SR-70, adquiriu caráter normativo, ${ }^{9}$ negando aplicabilidade imediata ao parágrafo $3^{\circ}$ do art. 192 da Constituição de 1988, que dependeria, segundo preconizado no parecer elaborado por Saulo Ramos, Consultor Geral da República à época, de regulamentação por lei complementar para que tivesse vigência.

Com base nesse parecer, o Banco Central do Brasil (BCB) editou a Circular 1.365, que esclarecia aos agentes do mercado financeiro que a legislação em vigor antes da promulgação da nova constituição permanecia vigente, aguardando a edição de lei complementar segundo determinava o art. 192 da nova Constituição para regulação do Sistema Financeiro Nacional. A limitação constitucional da taxa de juros aplicável ao mercado financeiro tornou-se então objeto de análise do STF, visto que o parecer proferido pela Consultoria Geral da República terminara por frear a aplicação desse dispositivo, contrariando diversos setores da sociedade que observavam a limitação constitucional como uma restrição ao setor financeiro em favor da cidadania e dos setores produtivos, que assim conquistavam uma importante vitória contra a prática da usura. Ao contrário, as autoridades financeiras e monetárias do País vislumbravam na aplicação daquele dispositivo um agravamento insustentável da crise financeira já vivenciada pelo país, que teria como conseqüências fenômenos como o fim da atividade de intermediação financeira exercida principalmente pelos bancos e a conseqüente formação de um mercado informal de crédito, a fuga de capitais, o fim do mercado de capitais, o aumento da hiperinflação e outros.

A questão da auto-aplicabilidade do parágrafo $3^{\circ}$ do art. 192 da Constituição ensejou interessante debate sobre métodos de interpretação constitucional, que tinha como substrato para a discussão e a localização do preceito dentro do artigo e sua redação, e a análise de sua construção, considerando critérios como seu caráter proibitivo e o conceito apresentado de juros reais. Os Ministros Sydney Sanches, relator do processo, Celso de Mello, Célio Borja, Octavio Gallotti, Aldir Passarinho e Moreira Alves declararam improcedente a ação, com base, em síntese, nos seguintes argumentos: (i) o artigo constitui um todo, devendo o parágrafo seguir o mandamento do caput, a não ser que o excepcione de modo expresso, o que não se verificaria na hipótese analisada. Assim, a aplicação do parágrafo $3^{\circ}$ dependeria de 
sua regulamentação por lei complementar, seguindo o caput do artigo 192; (ii) não há caracterização do que seriam juros reais, o que deveria então ser feito em lei, propiciando o cálculo dos juros cobrados pelas instituições financeiras e sua subsunção ou não ao mandamento constitucional; e (iii) não se pode punir por usura sem a caracterização do que são juros reais e a exata definição do tipo penal.

Portanto, a decisão da maioria pela improcedência da ação encontrou fundamento em argumentos formais e conceituais, que podem ser considerados como característicos de um julgamento de caráter dogmático-formal, que não agregou elementos de ordem extrajurídica, como aqueles apresentados no próprio Parecer SR-70 sobre os efeitos da limitação dos juros sobre o Sistema Financeiro, acompanhando análise realizada pelo BCB. A preocupação em se ater a uma pretensa racionalidade estritamente jurídica evidencia-se no seguinte excerto do voto do Ministro Célio Borja: "Desde que aqui estou, tenho procurado guardar-me de quaisquer considerações que não sejam estritamente jurídicas”. ${ }^{10}$ O STF, por meio de um raciocínio eminentemente dogmático-formal, evitou a limitação dos juros pela Constituição Federal, que era repelida pelas instituições financeiras e pelos órgãos de regulação financeira do Executivo com base em análise econômicas das conseqüências da limitação. Em outras palavras, o STF confirmou a decisão do Poder Executivo de frear a aplicação dessa limitação, consolidando a competência do CMN e do BCB para a regulação dos juros, sem recorrer a argumentos de ordem extrajurídica presentes no debate público sobre a questão.

Por outro lado, os Ministros que se posicionaram pela declaração da inconstitucionalidade do parecer analisado defenderam, a partir das lições de Ruy Barbosa, a eficácia plena do parágrafo $3^{\circ}$, pois os dispositivos que expressam proibições seriam em regra self-executing, conferindo um direito àqueles que operam no Sistema Financeiro, ao qual se contrapõe uma obrigação das instituições financeiras. Além disso, a referência a um conceito jurídico indeterminado como juros reais não significaria a inaplicabilidade da norma, mas sim a necessidade de concretização do conceito por meio da interpretação na atividade jurisdicional. Observa-se que os votos pelo provimento da ADI foram utilizados em muitos momentos de argumentos que extravasam os limites de uma argumentação jurídico-formal, incorporando elementos econômicos e sociais (de ordem extrajurídica).

A apertada votação, com placar de 6 x 4, decidiu pela necessidade de regulamentação do art. 192 da Constituição Federal por lei complementar, inclusive seu parágrafo $3^{\circ}$, garantindo desse modo a competência regulatória de conjuntura da burocracia financeira para a definição da taxa de juros, impedindo a definição constitucional dos juros. Portanto, a lógica da governabilidade foi preservada mediante a utilização pela corte de argumentos estritamente dogmático-formais, que, próximos de um parnasianismo jurídico, decidiram questão da mais alta importância com base em considerações acerca da topografia do artigo, considerando a localização do parágrafo 
em face do caput, e a definição ou não de um conceito, o de juros reais, como suficiente à aplicação da constituição.

Pode-se perceber neste caso a adequação do que é constitucional a partir das necessidades da governabilidade do País. A generalidade abstrata do direito é relativizada neste caso para adequar-se às demandas econômicas tidas como inexoráveis à época, em que uma catástrofe econômica era anunciada como conseqüência da limitação constitucional dos juros. ${ }^{11}$ A Constituição Federal não assumiu o papel de limitar e direcionar a ação pública, legitimando assim o processo decisório, apenas serviu como um instrumento de poder, exercido pelo STF, no sentido de conferir às autoridades monetárias brasileiras a competência para dirigir os juros praticados na economia segundo a lógica da governabilidade.

A utilização para tanto de uma argumentação de caráter intensamente dogmáticoformal, conferindo assim à sentença a aparência de uma decisão pautada unicamente no raciocínio jurídico, apartado de qualquer contingência econômico-social existente, consolidou, quanto aos diversos agentes sociais interessados, a concepção de que o STF entendeu ser necessário que o Sistema Financeiro Nacional fosse regulado por uma lei complementar única, por determinação do art. 192 da Constituição Federal. Essa crença transformou-se em uma espécie de mito, influenciando os casos relativos ao Sistema Financeiro Nacional que se seguiram. A despeito de essa tese não se sustentar em face da redação do caput e da análise do julgamento do STF na ADI n. 4, ${ }^{2}$ o mito da lei complementar única arraigou-se entre as autoridades de regulação financeira e os agentes financeiros, que proclamavam a necessidade de que apenas uma lei complementar regulamentasse toda a matéria financeira.

\subsection{A SUPERAÇÃo Velada de UM PRECEDENTE EM FACE do CONTEXTO ECONÔMICO}

Em 29.06.1995, foi promulgada a Lei n. 9.069, de caráter ordinário e resultante de aprovação, pelo Congresso Nacional, da Medida Provisória n. 542 e sucessivas reedições, que instituiu o Plano Real. No dia 04.07.1995, o Partido dos Trabalhadores impetrou ação direta de inconstitucionalidade contra os artigos $8^{\circ}, 9^{\circ}, 10$ e 11 dessa lei, alegando contrariedade ao caput do artigo 192 da Constituição Federal, que exigiria, segundo a petição inicial, que a matéria disciplinada pelos artigos questionados fosse disposta em lei complementar (ADI n. 1.312-2). Os dispositivos impugnados disciplinavam a organização do Conselho Monetário Nacional, alterando sua composição e procedimentos deliberativos.

O CMN, criado e disciplinado pela Lei n. 4.595/1964, tinha em sua composição o Ministro da Fazenda, que presidia o Conselho, o Presidente do Banco do Brasil, o Presidente do BNDES e outros sete membros indicados pelo Presidente da República e aprovados pelo Senado, que deveriam ser escolhidos entre brasileiros de ilibada reputação e notória capacidade em assuntos econômico-financeiros, com mandato de sete anos, admitida a recondução. A Lei n. 9.069/1995 reduziu a composição do Conselho 
a apenas três membros, o Ministro da Fazenda, que permaneceu como seu presidente, o Ministro do Planejamento, que no regime anterior apenas podia participar das reuniões e, se necessário, substituir o presidente no caso de sua ausência e falta do Ministro da Indústria e do Comércio, e, por fim, o Presidente do $\mathrm{BCB}$, que antes não participava do Conselho. Quanto aos procedimentos decisórios, as deliberações permaneceram exigindo apenas maioria, sendo atribuído ao Presidente do CMN, no novo regime, deliberar ad referendum do Conselho em casos de urgência e relevância.

A petição inicial do Partido dos Trabalhadores alegou ser autoritária a estrutura imposta pela lei questionada, criando um insulamento dos órgãos da burocracia financeira, pois afastaria setores expressivos da vida econômica, como os trabalhadores, instituições privadas e órgãos do execUtivo com maior potencial de controle social, da instância de discussão em que se dá o processo de formulação das políticas monetária, creditícia e cambial. O principal argumento presente na petição inicial para fundamentar a inconstitucionalidade das normas questionadas baseava-se na decisão do STF na ADI n. 4-7, que afirmou ser necessária uma lei complementar para a regulamentação do Sistema Financeiro Nacional, nos termos do caput do artigo 192 da Constituição Federal. Dessa forma, o CMN, como agente integrante do Sistema Financeiro Nacional, estaria sujeito à regulamentação por lei complementar, como aquela que o instituiu, a Lei n. 4.595/1964, recepcionada pela Constituição de 1988, segundo o STF, como lei complementar.

O relator reconheceu em seu voto a plausibilidade da afirmação de que o CMN estaria inserido no inciso IV do art. 192, contudo, não lhe atribuiu intensidade suficiente à concessão da liminar, uma vez que a objeção imponível a ela também teria relevância e plausibilidade. Isso porque também seria possível afirmar que não se inclui o CMN na expressão "instituições financeiras públicas”, contida no dispositivo constitucional considerado pelo Ministro, visto que, dada a estatura do CMN dentro do Sistema Financeiro Nacional, seria razoável exigir sua menção expressa como feito com o BCB, além do caráter superior do CMN em relação às entidades a ele subordinadas. Além disso, as disposições do art. 192 deveriam ser interpretadas em face da competência da lei ordinária e do decreto presidencial (artigos 48, XI, e 84, VI, da Constituição Federal) para a estruturação dos órgãos da administração pública, o que não excluía ainda a questão sobre definir se o inciso IV do art. 192 se referiria também ao CMN por meio da expressão genérica "instituições financeiras públicas”, já que este mesmo inciso se referiu expressamente ao $\mathrm{BCB}$, diferenciando-o das demais instituições financeiras públicas.

O STF negou provimento ao pedido cautelar por unanimidade, em 19.10.1995. A inserção das medidas analisadas no contexto de implantação do Plano Real trouxe novamente ao STF a necessidade de conciliar em sua decisão questões de ordem dogmático-formal trazidas pelo requerente, em face do contexto das medidas implantadas pelo Poder Executivo. Neste caso, conforme aponta a Exposição de Motivos 
Interministerial n. 205/MF/SEPLAM/MJ/MTB/MPS/MS/SAF da Medida Provisória n. 542, a mudança na composição do Conselho era necessária ao alcance da autonomia da autoridade monetária, que não poderia se subordinar a pressões políticas e econômicas, de modo a realizar assim a consolidação do novo padrão monetário. Portanto, a nova composição procurava assegurar maior capacitação técnica às decisões do CMN para o alcance da estabilidade monetária, ressaltando a gestão tecnocrática da moeda e do crédito em detrimento da transparência das decisões e da participação da sociedade no processo decisório.

Por conseqüência, o STF tinha diante de si o conflito entre a análise formal da constitucionalidade do dispositivo e a relevância das alterações implantadas pelas disposições analisadas à nova política monetária do país, que conseguia limitar os efeitos da inflação, que devastavam a economia nacional desde a metade da década de 1980 . Mais uma vez o tribunal não esclareceu esse conflito e limitou sua discussão a uma confusa análise acerca dos requisitos formais da Lei n. 9.069/1995, subvertendo a lógica da reserva de lei complementar para a regulamentação do Sistema Financeiro Nacional estabelecida na ADI n. 4-7. Naquele caso, a necessidade de evitar a aplicação da taxa de juros de $12 \%$ ao ano foi determinante para que a corte vinculasse todo ato de regulação do Sistema Financeiro à lei complementar, que deveria dispor sobre todas as matérias concernentes a esse setor. Assim, na ADI n. 4-7, a confirmação da decisão do Poder Executivo se deu por meio de uma argumentação de caráter dogmático-formal, que impôs à intervenção estatal no Sistema Financeiro Nacional a necessidade de respeito a requisitos formais mais intensos, ou seja, o procedimento para edição de lei complementar. Em outras palavras, aquela decisão exaltou o raciocínio legal-racional como modo de legitimação da decisão do Poder Executivo e do STF, entretanto, a racionalidade legal-racional ia de encontro às políticas do Poder Executivo na crise inflacionária e bancária vivenciadas pelo País entre 1980 e meados da década de 1990, baseadas em uma lógica de governabilidade, o que resultou na apresentação pelo STF de uma argumentação frágil que procurava demonstrar a inexistência ou a incerteza sobre a caracterização do vício formal, contrariando a decisão da ADI n. 4, geralmente anunciada como precedente da corte em matérias de Sistema Financeiro. Essas mesmas observações são válidas para os dois próximos casos aqui analisados.

A crise bancária de meados da década de 1990 exigiu maior intervenção das autoridades monetárias brasileiras, notadamente o Conselho Monetário Nacional $(\mathrm{CMN})$ e o $\mathrm{BCB}$, tendo em vista a real possibilidade de que a crise existente se intensificasse e atingisse um maior número de instituições. A regulação do sistema financeiro pretende a definição do risco a ser suportado pelas instituições financeiras em sua atividade, tendo em vista a proteção dos investidores e do sistema como um todo. Assim, realizam-se no sistema bancário habitualmente dois tipos de regulação: a prudencial e a sistêmica. A regulação prudencial constitui um mecanismo de 
regulação apriorístico, que procura garantir a higidez do sistema bancário mediante a supressão da incapacidade dos depositantes de aferirem a situação patrimonial dos bancos. Portanto, procura essencialmente proteger os interesses dos depositantes, criando limites à exposição das instituições bancárias a riscos, o que contribui subsidiariamente à manutenção da normalidade no sistema. A regulação sistêmica, que objetiva principalmente evitar uma crise bancária, compreende um conjunto de técnicas regulatórias de caráter emergencial, implementadas a partir da verificação de um evento sistêmico com o fim de evitar uma crise sistêmica. Os principais mecanismos de intervenção utilizados pelas autoridades monetárias são seguro de depósito e a atuação do Banco Central como emprestador de última instância. ${ }^{13}$

Em meio a essa crise, foi lançado o Programa de Estímulo à Reestruturação e Fortalecimento do Sistema Financeiro Nacional (Proer), criado pela Resolução n. 2.208 do CMN e implementado por meio de outras resoluções desse órgão e medidas provisórias, que ampliava o poder de fiscalização e intervenção do CMN e do $\mathrm{BCB}$, atribuindo-lhes uma série de ações que poderiam ser adotadas com o intuito de evitar uma crise bancária. Portanto, o Proer constituía um plano de intervenção dos agentes reguladores do sistema financeiro para a contenção da crise bancária vivenciada pelo Brasil na metade da década de 1990, que ameaçava desestabilizar a atividade financeira e por conseqüência toda a economia do País, que naquele momento se recuperava da crise inflacionária recém-superada.

Em 13.11.1995, o Partido dos Trabalhadores ajuizou ação direta de inconstitucionalidade com pedido de medida liminar contra a Medida Provisória n. 1.179, de 03.11.1995, que regulava o Proer. Essa Ação Direta de Inconstitucionalidade recebeu o número 1.376-9 e reclamava pela inconstitucionalidade dos três artigos que compõem a medida provisória por legislarem sobre matéria reservada pelo artigo 192 da Constituição Federal à lei complementar, o que teria sido confirmado pelo STF na ADI n. 4-7.

O relator, Ministro Ilmar Galvão, analisou a questão aventada sob o prisma da necessidade de lei complementar para dispor sobre regulação do Sistema Financeiro Nacional. Negou então o relator a declaração de inconstitucionalidade do dispositivo em função dessa alegação, apresentando como justificada a atuação do Presidente da República por meio de medida provisória. Isso porque esta não pretendia inovar no campo reservado à lei complementar pelo artigo 192 da CF, uma vez que o Proer havia sido criado pela Resolução n. 2.208 do CMN, de modo a serem apenas complementares as disposições da medida provisória àquela resolução. Explica que a Lei n. 4.595/1964, recepcionada pela Constituição de 1988, atribuía ao CMN a competência para "zelar pela liquidez e solvência das instituições financeiras" (art. 2. ' , VI). Portanto, exerceu o CMN corretamente sua competência, e a medida provisória impugnada, por simplesmente regulamentar a resolução do CMN, não seria inconstitucional. O voto do relator, acompanhado por uma série de Ministros evidencia 
que: (i) o STF reconheceu a competência normativa do CMN para regular o Sistema Financeiro Nacional, que neste caso excedia inclusive à do próprio Presidente da República; e (ii) o STF admitiu que uma medida provisória, que está no mesmo nível hierárquico de uma lei ordinária, simplesmente regulamentasse uma resolução do CMN, que era competente para inovar juridicamente.

Neste caso, novamente se observa a subversão da lógica imprimida na ADI n. 47 em função do contexto econômico e de governabilidade, o que é evidenciado pelo Ministro Maurício Corrêa, cujo voto é transcrito na íntegra:

Sr. Presidente, essas medidas, na verdade, foram tomadas em face do momento econômico-financeiro por que passa o país. O paradigma foi o fenômeno ocorrido na Venezuela. Quando lá estive, na época da quebra do Banco Latino, pude verificar que foi desencadeada uma total desorganização em seu sistema financeiro. Apenas citei esse fato para ressaltar a real necessidade da adoção dessas medidas pelo Governo brasileiro. Desse modo, também não vejo nenhuma inconstitucionalidade. Por isso, acompanho o eminente Relator, indeferindo a media cautelar. ${ }^{14}$

De outro lado o Ministro Marco Aurélio ressalta a necessidade de respeito aos ditames constitucionais mesmo quando crises exijam medidas emergenciais, exaltando assim a racionalidade legal-racional do direito em face da lógica da governabilidade: "Por isso, peço vênia ao nobre Relator para, potencializando, sim, a Carta Política da República, no que representa segurança para toda a sociedade e não uma política governamental momentânea, deferir a liminar pleiteada”. ${ }^{15}$

Entre as medidas adotadas no âmbito do Proer, as Resoluções do CMN de números 2.197, de 31.08.1995, e 2.211, de 16.11.1995, instituíam o Fundo Garantidor de Créditos (FGC), um mecanismo de regulação sistêmica denominado seguro de depósito. O seguro de depósito funciona como uma garantia aos correntistas de um banco, à medida que assegura o pagamento de parte ou do total dos depósitos feitos em um determinado banco. No caso do FGC, o fundo constituído visava a garantir o crédito dos depositantes, estabelecido o teto de R\$20 mil (vinte mil reais) por titular, em face de instituições financeiras participantes do fundo e que estivessem sujeitas à intervenção, liquidação extrajudicial ou falência, ou de instituições reconhecidas como insolventes pelo Banco Central mesmo que não estivessem sujeitas a esses regimes. ${ }^{16}$ Como já mencionado, o Brasil enfrentava intensa crise financeira na metade da década de 1990, de modo que essa medida procurava recuperar a confiança que o investidor depositava na instituição financeira onde possuía aplicações. Isso porque a confiança no setor bancário é algo imprescindível, capaz de evitar possíveis corridas bancárias, que teriam efeitos catastróficos sobre os sistemas monetário e econômico. 
Essas resoluções foram questionadas na ADI n. 1.398-0, também proposta pelo Partido dos Trabalhadores, em 26.01.1996. Seriam formalmente inconstitucionais por não respeitarem a exigência de lei complementar para a criação de fundo ou seguro para a garantia de créditos, aplicações e depósitos, com o objetivo de proteger a economia popular, conforme determinaria o caput do artigo 192 e seu inciso VI da Constituição Federal de 1988, que proibia a utilização de recursos da União na formação do fundo ou seguro. A inconstitucionalidade se originaria também da violação do artigo 167, incisos VIII e IX, que proibiam, respectivamente, a utilização de recursos dos orçamentos fiscais para suprir necessidades ou déficits de empresas, fundações ou fundos sem autorização legislativa específica, e instituição de fundos de qualquer natureza sem autorização legislativa. Por fim, outra inconstitucionalidade residiria na extinção do Fundo de Garantia de Depósitos e Letras Imobiliárias (FGDLI) e da Reserva para a Promoção da Estabilidade da Moeda e do Cheque (Recheque), transferindo os recursos públicos dos quais se constituíam para um fundo privado.

O relator Ministro Francisco Rezek reconhece a necessidade de lei complementar para regular o sistema financeiro, inclusive para a criação de fundo ou seguro para a proteção da economia popular, em referência ao FGC. Contudo, apesar de reconhecer a existência do bom direito para a concessão da liminar, Rezek admite a configuração do periculum in mora, também elemento essencial à concessão de um pedido cautelar, somente no que concerne à utilização de recursos públicos na composição de um fundo privado. Nesse sentido, vota no sentido de conceder a liminar para suspender a eficácia dos artigos das resoluções em análise que disciplinavam a utilização de recursos do FGDLI e do Recheque na formação do FGC. Maurício Corrêa define o voto do relator como o "caminho mais adequado ao deferir o possível”. ${ }^{17}$ E assim justifica:

E o faz bem, tendo-se em vista que as medidas preconizadas nas normas questionadas, objeto desses atos do Banco Central do Brasil, visam exatamente a proteção do pequeno poupador. Já, pois, superposta a questão superficial, conveniência social de alta relevância, que pelo seu próprio conteúdo, indica seja preservado o princípio a que visaram as respectivas Resoluções ${ }^{18}$ (grifos nossos).

Como no Caso Proer, o Ministro Maurício Corrêa apresenta questões de ordem não estritamente jurídica. Entretanto, novamente o faz de modo genérico e pouco claro. O trecho é confuso, e mal permite compreender qual seria a "questão superficial superposta”. Seria essa questão o vício formal na criação do fundo? Pode-se tratar como superficial uma inconstitucionalidade reconhecida? Cumpre ainda citar os seguintes excertos do voto do Ministro Marco Aurélio, que acompanhou o Relator: 
Senhor Presidente, creio que todos nós estamos de acordo quanto à plausibilidade jurídica do pedido, no seu todo. Costumo dizer que as coisas se complicam sempre quando há falha em atividade desenvolvida por determinada instituição. Refiro-me ao Congresso Nacional no que, passados oito anos, ainda não editou a lei complementar de que cogita o artigo 192 da Carta Federal. [...] Senhor Presidente, não fosse a repercussão do deferimento de uma liminar em maior extensão, considerados principalmente os pequenos investidores, os pequenos correntistas, não teria a menor dúvida em atuar no campo pedagógico, sinalizando ao autor do ato atacado que ele também deve obediência à Lei Maior, à Constituição Federal. Sensibiliza-me, contudo, o que foi dito relativamente à necessidade de manter-se, com eficácia, parte do diploma atacado visando a proteger justamente esses pequenos investidores. Assim, projeto o exame do vício formal para o julgamento da ação direta de inconstitucionalidade ${ }^{19}$ (grifos nossos).

O Ministro Marco Aurélio, como resta óbvio da análise desses excertos, reconhece a inconstitucionalidade das resoluções do CMN, contudo, ao considerar que os efeitos de sua decisão poderiam reverberar de modo indesejável, restringe os limites da liminar, nos termos do voto do relator, ou seja, para impedir somente a utilização de recursos públicos na constituição do FGC. Dessa forma, decidiu pela lógica da governabilidade, em oposição a seu voto no caso Proer, em que rejeitou que alusões à governabilidade e medidas urgentes pudessem exceder os limites impostos pela Constituição Federal. Esse foi o resultado unânime no julgamento do pedido liminar.

Assim, confirmou o STF, nesses três casos que se passam entre 1995 e 1996, as decisões do Poder Executivo a despeito da alegação de vício formal. Interessante observar que nesses casos não houve julgamento de mérito das ações, de modo a evitar a emergência de coisa julgada e de um possível precedente envolvendo a desconsideração de questões formais pelo STF. Isso porque após o julgamento do pedido cautelar os processos permaneceram sem andamento até que perdessem objeto e fossem por conseqüência arquivados. As Ações n. 1.312-2 e 1.398-0 perderam o objeto em função da alteração na redação do artigo 192, o que teria tornado o pedido prejudicado, segundo a corte.

Os casos evidenciam uma tensão entre racionalidades, situação em que o Tribunal deparava-se com uma contraposição entre o raciocínio dogmático-formal, pautado na busca pela legitimação legal-racional, e o contexto material da situação em pauta, que trazia problemas relacionados à governabilidade, o que pode ter levado a corte a desenvolver mecanismos informais de decisão. Possível dizer que o STF "decidiu não decidir", ou seja, esclarece ser a norma inconstitucional, mas adia essa declaração para o julgamento de mérito, que termina por não ocorrer. Essa estratégia teria permitido ao STF evitar a formalização em sentenças de mérito de decisões 
contraditórias nesses casos, impedindo assim a formação de um precedente no sentido de permitir a inconstitucionalidade em contextos de crise de governabilidade. ${ }^{20}$

A tensão verificada pode ser confirmada mediante a análise de outras ações diretas de inconstitucionalidade analisadas pelo STF, mas que não apresentavam uma questão de governabilidade em seu centro, como as Ações Diretas de Inconstitucionalidade n. 2.223-7 e 2.244-0. A Emenda Constitucional n. 13 de 1996 extinguiu o monopólio da atividade de resseguros no Brasil, antes garantido ao IRBBrasil Resseguros S.A. (IRB-Brasil RE). Dessa forma, o mercado de resseguros abriu-se à atuação das empresas seguradoras nacionais e estrangeiras, o que exigiu que a regulamentação do setor fosse reestruturada, uma vez que, antes dessa Emenda, o IRB-Brasil RE, além de único agente atuante, era responsável pela organização da atividade de resseguros, seguindo as diretrizes do Conselho Nacional de Seguros Privados (CNSP), segundo os termos do Decreto-lei n. 73/1966, que foi recepcionado pela Constituição Federal de 1988 como lei complementar. A nova conformação da regulação do setor de resseguros foi implementada pela Lei Ordinária n. 9.932, de 20.12.1999, que transferiu as funções regulatórias e de fiscalização do setor de resseguros, antes atribuídas ao IRB-Brasil RE pelo Decreto-lei n. 73/1966, à Superintendência de Seguros Privados (Susep). Essa lei foi questionada perante o STF em duas ações diretas de inconstitucionalidade propostas pelo Partido dos Trabalhadores, que alegava, essencialmente, violação ao artigo 192 da Constituição Federal, principalmente seus incisos II e IV. Concluem então que, como a matéria é reservada à lei complementar, a lei ordinária é certamente inconstitucional, visto que não poderia modificar nem revogar a lei anterior, pois são de tipos distintos. O STF verificou então a existência do vício formal, correspondente à veiculação por lei ordinária de disciplina reservada à lei complementar, com base no mesmo artigo da Constituição Federal analisado nos outros casos aqui discutidos. No entanto, essa demanda não apresentava como pano de fundo questões diretamente ligadas à moeda e ao crédito, inseridas em crises financeiras.

\section{REFORMA CONSTITUCIONAL: SUPRESSÃO DO ÔNUS ARGUMENTATIVO}

A alteração do artigo 192 pela Emenda Constitucional n. 40, promulgada em 2003, que suprimiu todos seus incisos e parágrafos, subtraindo diversas indicações e exigências expressas de lei complementar, modificou os pressupostos do raciocínio formal da ADI n. 4. A manutenção da necessidade de que leis complementares (expressamente no plural após essa emenda) regulamentassem o Sistema Financeiro resultou em uma interpretação restrita dessa disposição pelo STF, que nas Ações Diretas de Inconstitucionalidade n. 2.591 e 3.289-5 consideraram não ser necessária lei complementar para regulamentar as questões naqueles casos analisadas, sem proporcionar nenhuma sinalização sobre que matérias estariam sujeitas à lei 
complementar, manifestando o casuísmo nessa definição. Interessante observar que à modificação do artigo 192 corresponde, nessas ações, a análise do mérito das ações pelo STF, que se desincumbiu em grande parte do ônus argumentativo que sobre a Corte pendia quando da vigência do artigo 192 em sua redação original e o precedente a ele relativo na ADI n. 4. Em outras palavras, a redução do artigo 192, com a extinção de seus incisos e parágrafos, resultou em maior liberdade à atividade interpretativa do STF, que teve menos dificuldade em justificar suas decisões.

É o que se observa nas Ações Diretas de Inconstitucionalidade n. 2.591 e 3.2895, referidas acima. Na primeira delas, o STF analisou a aplicabilidade ou não do Código de Defesa do Consumidor (Lei n. 8.078/1990) às instituições financeiras, afastando de modo uníssono a necessidade de que a disciplina consumerista das atividades financeiras se desse por lei complementar. Cumpre observar que a decisão do Tribunal nesse caso não permite uma precisa compreensão da opinião da Corte sobre a questão dos juros praticados por instituições financeiras e a atuação do Poder Judiciário baseado no CDC. Essa questão, que se apresentava como a mais relevante indagação presente no caso, exigindo da Corte uma definição, continua sem uma resposta precisa, dado que a leitura do acórdão da ação direta de inconstitucionalidade e dos embargos de declaração posteriormente opostos não esclarece com exatidão os termos da decisão. Pode-se afirmar, não sem alguma incerteza sobre a precisão da afirmação, que a maioria dos Ministros atribui a determinação dos juros a uma decisão de política monetária, que deve ocorrer no âmbito macroeconômico, sendo a atuação do Poder Judiciário restrita à coibição de abusos contratuais. Entretanto, os limites e a disciplina da atuação do Poder Judiciário nessas questões não está clara, pois não se definiu, por exemplo, se os abusos contratuais seriam coibidos com base no CDC ou nos dispositivos do Código Civil. Assim, a obscuridade e confusão dos acórdãos poderá resultar em diversas decisões judiciais em esferas inferiores que realizarão julgamentos em sentidos distintos, contudo, sob a prerrogativa de utilizar um precedente do STF, que pelas características mencionadas permite sua utilização para a fundamentação em sentidos opostos. É o caso, por exemplo, da utilização apenas da ementa sem referência aos votos. A leitura e aplicação apenas da ementa resultante do julgamento dos embargos não permitem nenhuma inferência acerca da limitação do âmbito de atuação do Poder Judiciário e da lei ordinária, apresentando a aplicação do CDC ao Sistema Financeiro como irrestrita. Entretanto, o mesmo não pode ser verificado nos votos dos Ministros que integram a maioria.

Já a ADI n. 3.289-5 analisava a Medida Provisória n. 207, publicada no Diário Oficial da União em 16.08.2004, que continha como elemento principal a caracterização do Presidente do Banco Central como Ministro de Estado. Dessa forma, o $\mathrm{BCB}$, que constituía uma autarquia federal segundo determinação do artigo $8^{\circ}$ da Lei n. 4.595/1964, passaria a ser presidido por um Ministro de Estado. Durante o julgamento, essa medida provisória foi convertida em lei ordinária pelo Congresso 
Nacional. A motivação para essa alteração no status jurídico do Presidente do BCB era atribuída pela imprensa a diversas acusações de sonegação fiscal e movimentação financeira irregular contra o atual Presidente do BCB, Henrique Meirelles. Nessa hipótese, o Presidente da República teria utilizado um instrumento emergencial como a medida provisória para "blindar" institucionalmente Henrique Meirelles, que passaria a ter prerrogativa de foro, de modo a ser julgado pelo STF.

O voto do relator, Ministro Gilmar Ferreira Mendes, foi acompanhado pela maioria, que ratificou assim a contradição existente no voto desse Ministro: para justificar a medida segundo os requisitos de urgência e relevância, Gilmar Ferreira Mendes procurou demonstrar a importância da medida provisória ao exercício das funções de Presidente do BCB, que seriam de extrema relevância à "vida nacional", devendo por isso estar livre de pressões externas. Entretanto, no que concerne à alegação de necessidade de lei complementar para a regulamentação do Sistema Financeiro, emprega o mesmo tratamento jurídico despendido aos demais funcionários do banco, inclusive quanto a suas atribuições, já que não influenciariam, nesse sentido, a estrutura do Sistema Financeiro Nacional. Isso porque afirma ser questão de mera organização administrativa, relacionada a questões já tratadas pelo STF sobre funcionários do BCB. Dessa forma, seria desnecessária uma lei complementar para tal regulamentação. Por fim, a Corte, por maioria, declarou improcedente a ação e confirmou o status de ministro concedido ao Presidente do BCB.

Com o "encolhimento" do artigo 192, o STF evitou o julgamento do mérito das Ações Diretas de Inconstitucionalidade n. 1.312-2, 1.398-0, 2.223-7 e 2.244-0, analisadas no item 3.2, por considerar prejudicado o pedido, tendo em vista a alteração na disciplina constitucional, que resultou em perda do objeto da ação. Dessa forma, o STF não precisou se pronunciar, no mérito, sobre ações cujo julgamento cautelar havia evidenciado a inconstitucionalidade formal sem que a norma questionada fosse declarada inconstitucional.

\section{Conclusão: QUAL O PAPEL DA CoNSTITUiÇÃo?}

No período que se seguiu ao julgamento da ADI n. 4, em 1991, até a promulgação da Emenda Constitucional n. 40, em 2003, ou seja, aproximadamente doze anos, nenhuma ação direta de inconstitucionalidade que discutisse alguma questão relativa à regulamentação do Sistema Financeiro Nacional proposta perante o STF foi apreciada em seu mérito. O julgamento do STF na ADI n. 4 estabeleceu que o Sistema Financeiro deveria ser regulamentado por lei complementar. Mais do que isso, essa decisão transformou-se num mito, um dogma, entre instituições financeiras, órgãos da imprensa, legisladores e agentes do Poder Executivo, que entendiam ter o STF definido como necessário que uma única lei complementar regulamentasse todo o Sistema Financeiro, uma vez que o caput do artigo 192 da Constituição 
Federal trazia a expressão lei complementar no singular. ${ }^{21}$ Essa crença, pouco sustentável em face da redação do artigo 192 da Constituição Federal e da própria decisão do STF na ADI n. 4, além de dificultar ou quase impossibilitar a atividade legislativa do Congresso Nacional nesse ponto, já que os custos políticos de regulamentar toda a atividade do Sistema Financeiro Nacional de uma só vez eram quase insustentáveis, criou um precedente sempre invocado perante o STF, exigindo desse tribunal sua consideração nas decisões supervenientes.

Conforme já discutido, o contexto em que foi julgada a ação parece ter influenciado a decisão do Tribunal, que procurou uma fundamentação essencialmente formal para evitar que argumentos de ordem econômica muito difundidos à época se observassem, como a possibilidade ventilada de que o Sistema Financeiro Nacional se extinguiria se os juros fossem limitados a $12 \%$ ao ano. A constituição dessa lógica formal, com uma clara ratio decidendi no sentido de exigir que o Sistema Financeiro Nacional fosse regulamentado por lei complementar, seja uma única lei ou várias, resultou na tensão entre racionalidade formal e material apresentada nos casos aqui analisados.

Em outras palavras, no julgamento da ADI n. 4, os argumentos de caráter dogmático-formal, pautados na racionalidade legal-racional do direito, eram capazes de confirmar uma decisão do Poder Executivo, que impediu a aplicação da taxa de juros estabelecida constitucionalmente e garantir a governabilidade, considerando o contexto econômico presente no caso. Entretanto, nos casos que se seguiram, essa mesma lógica constituía empecilho à realização das decisões do Poder Executivo, já sancionadas ou não pelo Congresso Nacional. Conseqüentemente, o STF teve que considerar nesses casos a questão formal da reserva de lei complementar consagrada pela própria Corte, em face de decisões relevantes no contexto econômico do país, que exigiam a subversão da lógica imprimida pela Corte na ADI n. 4. Não obstante a dissonância em relação ao precedente mais importante em matéria de Sistema Financeiro, o STF, nas Ações Diretas de Inconstitucionalidade n. 1.312-2, 1.376-9 e 1.398-0, julgadas entre 1995 e 1996, não declarou a inconstitucionalidade das normas questionadas, apesar dos vícios formais existentes e muitas vezes reconhecidos pelos Ministros.

Esses casos, após o indeferimento da medida cautelar, permaneceram estagnados durante anos, tendo sido extintos por perda do objeto, em função das alterações realizadas pela Emenda Constitucional n. 40 no art. 192 da Constituição. Importa, contudo, perceber que a Corte evitou, com a paralisia no andamento dos processos, o julgamento de mérito dessas ações. Numa análise de mérito poderia ser mais difícil ao STF desconsiderar vícios formais evidentes para a legitimação de uma política implementada pelo Poder Executivo, transformando essa desconsideração das formalidades em sentença transitada em julgado e sua constituição como precedente. ${ }^{22}$ A partir da racionalidade formal instituída pela ADI n. 4, os julgamentos posteriores procuraram afastar a necessidade de lei complementar mediante uma argumentação que pode ser qualificada como frágil e inconsistente, que se esforçava para se ater a 
argumentos dogmático-formais e preservar a governabilidade, sem descuidar da legitimação das medidas perante o direito.

Cumpre questionar neste ponto se a Constituição Federal de 1988, como marco jurídico de uma nova conformação social do Brasil, conseguiu contribuir para a estabilização monetária e desenvolvimento econômico e social do país, à medida que tenha se apresentado como um direcionador da ação pública. Verifica-se nas decisões analisadas que as políticas públicas implementadas pelo Estado brasileiro no setor financeiro enfrentavam o desafio da governabilidade, dado o contexto de crise econômica, mediante o comprometimento da ordem constitucional, que era testada constantemente em pleno STF. O tribunal constitucional ao lidar com essa tensão foi incapaz de conciliar de modo coerente e transparente a dualidade governabilidade e legitimação legal das medidas analisadas, uma vez que, ao procurar preservar a governabilidade, apenas aparentava não descuidar dos pressupostos e premissas trazidos pela Constituição. Isso porque o texto constitucional não serviu nos casos analisados como vetor indicativo dos parâmetros da ação do Estado, que atuou segundo as conveniências da governabilidade e teve suas decisões confirmadas pelo STF, que conferiu a elas a legitimidade jurídica esperada a partir de argumentos confusos, contraditórios e incoerentes, adaptando o texto constitucional às contingências da governabilidade.

Não se defende aqui uma aplicação inconseqüente da letra fria da lei, mas sim a aplicação do texto constitucional como um vetor que direciona a ação pública, que, caso deva ser parcialmente desconsiderado em situações emergenciais, o seja de modo claro e evidente, com a demonstração e justificação do caráter excepcional da situação e da necessidade da medida inconstitucional. Nesse sentido, importante a distinção entre a declaração de inconstitucionalidade e a declaração da nulidade da norma inconstitucional, com a possibilidade de restringir os efeitos da decisão, como permite atualmente o artigo 27 da Lei n. 9.868/1999.

A Constituição Federal em matéria de Sistema Financeiro Nacional teve sua trajetória institucional marcada por esse papel instrumental à lógica da governabilidade, o que se torna evidente com a Emenda Constitucional n. 40/2003, que empreendeu o "encolhimento" do artigo 192, reduzindo o ônus argumentativo imposto ao STF para a legitimação das políticas implementadas pelo Poder Executivo, muitas vezes sancionadas pelo Poder Legislativo, na regulação do Sistema Financeiro Nacional. Pode-se dizer, em outras palavras, que essa alteração constitucional representa, ao suprimir premissas jurídicas, a prevalência da lógica econômica da governabilidade sobre a lógica jurídica da calculabilidade no que concerne ao Sistema Financeiro Nacional. Essa observação se confirma à medida que notamos existir uma deferência do STF às decisões emanadas do Poder Executivo sobre política monetária, juros e setor bancário, uma vez que foram todas elas confirmadas pelo STF. 


\section{NOTAS}

1 Discente do $5^{\circ}$ ano da graduação da Faculdade de Direito da USP.

2 Cf. Faria (1993, p. 12 et seq.)

3 A diferenciação entre governabilidade e legitimidade legal-racional, que será explorada com maior precisão no capítulo 3, é proposta por Faria (1993, p. 15 et seq).

4 Esta monografia foi realizada sob a orientação do professor Emerson Ribeiro Fabiani, tendo sido apresentada à Sociedade Brasileira de Direito Público em 04.12.2007, quando foi aprovada com distinção pelos professores que compunham a banca examinadora, o próprio orientador e o professor Diogo Rosenthal Coutinho. Este trabalho pode ser encontrado no sítio eletrônico daquela instituição: <www.sbdp.org.br>.

5 O sítio eletrônico do STF é <www.stf.gov.br>. A inclusão dos critérios "prox1" e "nao" significava, respectivamente, a delimitação da distância entre as palavras "sistema" e "financeiro" a no máximo uma palavra, e a exclusão do vocábulo "habitação", para evitar resultados relacionados ao Sistema Financeiro de Habitação.

6 Duas ações diretas encontradas não foram consideradas por tratarem de controle de constitucionalidade de norma estadual, o que escapa aos objetivos da pesquisa, pois não propiciam o estudo da análise do STF quanto a decisões do Poder Executivo pautados na especificidade técnica do Sistema Financeiro, uma vez que apenas o Poder Executivo Federal é composto por órgãos da burocracia financeira, como o CMN e o BCB. As ações diretas de inconstitucionalidade números 504, 2.317 e 1.155 também não serão consideradas porque, a despeito de conterem o vocábulo "sistema financeiro" em suas ementas, não tratavam diretamente de questão concernente a esse setor.

7 O Estado de Sítio está previsto em nossa Constituição nos artigos 137 e seguintes, que prevêem como hipóteses para sua decretação: "I - comoção grave de repercussão nacional ou ocorrência de fatos que comprovem a ineficácia de medida tomada durante o estado de defesa; II - declaração de estado de guerra ou resposta a agressão armada estrangeira".

8 Cf. Ferreira Filho (1990, p. 46-48).

9 Conforme determinavam os artigos 22 e 23 do Decreto n. 92.889, de 1986, a aprovação de um parecer da Consultoria Geral da República pelo Presidente da República e sua publicação conferem caráter normativo ao parecer, vinculando os órgãos da administração pública à sua disciplina.

10 ADI n. 4-7, p. 232.

11 Saulo Ramos, autor do parecer questionado, narra a reação do governo à limitação dos juros: "No dia 4, véspera da promulgação, fui chamado urgentemente ao gabinete do presidente da República. Reunidas, as autoridades financeiras e monetárias. Todas com cara de cortejo fúnebre, convencidas de que os juros de $12 \%$ ao ano entrariam em vigência na promulgação da Constituição, dia seguinte. Era o fim do mercado de capitais, dos mútuos, dos empréstimos, dos contratos bancários. [...] Propus a solução. O Ministro Mailson da Nóbrega faria uma consulta oficial ao Presidente, que a encaminharia ao consultor-geral da República. Proferido o parecer (tinha eu convicção da necessidade de lei para quase todos os preceitos do art. 192), o Presidente da República o aprovaria e, assim municiado, o Banco Central, obrigado a obedecer aos atos normativos da Presidência da República, distribuiria instruções para todo o sistema financeiro, e continuariam as regras vigentes" (FHC, juros e restaurante Folha de S. Paulo, 3 de out. 1998. Disponível em: <http://www1.folha.uol.com.br/fsp/opiniao/fz2603200309.htm>. Acesso em: 5 set. 2007).

12 Cf. Luís Virgílio Afonso da Silva e Jean Paul Cabral Veiga da Rocha, A regulamentação do Sistema Financeiro Nacional: o art. 192 e o mito da lei complementar única, p. 82-84.

13 O risco sistêmico está subordinado à verificação de um evento sistêmico, que se compõe por um acontecimento gerador do evento sistêmico, denominado "choque", e por mecanismos capazes de propagar o choque ("mecanismos de propagação”). No sistema bancário os choques podem ser acontecimentos como a quebra de uma ou mais instituições ou a divulgação de informações sobre a situação patrimonial dessas instituições, que podem, pelo mecanismo de propagação, afetar outras instituições financeiras. A estrutura patrimonial dos bancos e o modo como se dá sua relação com os clientes 
intensificam os possíveis mecanismos de propagação de um eventual choque, capaz de desencadear um evento sistêmico. Isso porque o descasamento entre ativo e passivo e a assimetria de informações existentes entre os bancos e seus clientes pode transformar uma crise de confiança em uma corrida bancária, uma vez que a crise de uma instituição bancária pode abalar a confiança em todo o sistema de garantir a liquidez dos depósitos. Além desse mecanismo informacional de propagação, é possível apontar também o referente às exposições reais entre bancos. Os bancos se relacionam entre si para fazer compensações e transferências entre instituições originadas das relações organizadas pelo sistema de pagamentos e para o controle de liquidez das instituições, por intermédio do mercado interbancário, à medida que um banco pode financiar a necessidade de liquidez de outro. Discussões acerca do conceito e desdobramento do risco sistêmico podem ser encontradas em Corte (2002, p. 319 et seq.), e De Bandt e Hartmann (2000, p. 10 et seq.)

14 ADI n. 1.376-9, p. 25.

15 ADI n. 1.376-9, p. 27.

16 O FGC permanece existindo, mas apresenta modificações, como o limite de depósitos garantidos (hoje até R\$ $60.000,00$ por depósitos em um mesmo conglomerado financeiro) e os tipos de aplicações cobertas. Mais informações podem ser obtidas no sito eletrônico do $\mathrm{BCB}$ (www.bcb.org.br) ou no sítio eletrônico do próprio fundo (www.fgc.org.br).

17 ADI n. 1.398-0, p. 28.

18 ADI n. 1.398-0, p. 28.

19 ADI n. 1.398-0, p. 29 et seq.

20 Rocha (2004, p. 130 et seq.).

21 Cf. Silva e Rocha (2002, p. 89).

22 Cf. Rocha (2004, p. 134).

\section{REFERÊNCIAS BIBLIOGRÁFICAS}

CAMPILONGO, Celso Fernandes; ROCHA, Jean Paul Cabral Veiga da; MATTOS, Paulo Todescan Lessa (Org.). Concorrência e regulação no Sistema Financeiro. São Paulo: Max Limonad, 2002.

CORRIGAN, Gerald. Are Banks Special?. Annual Report Essay, Federal Reserve Bank of Minneapolis, 1982. Disponível em: <http://www.minneapolisfed.org/pubs/ar/ar1982a.cfm>. Acesso em: 11 set. 2007.

CORTEZ, Tiago Machado. O conceito de risco sistêmico e suas implicações para a defesa da concorrência no mercado bancário. In: CAMPILONGO, Celso Fernandes et al. (coord.). Concorrência e regulação no sistema financeiro. São Paulo: Max Limonad, 2002, p. 319 et seq.

DE BANDT, Olivier; HARTMANN, Philipp. Systemic Risk: a Survey, Working Paper, n. 35, European Central Bank, 2000. Disponível em: http://www.ecb.int/pub/pdf/scpwps/ecbwp035.pdf

FARIA, José Eduardo. Direito e economia na democratização brasileira. São Paulo: Malheiros, 1993.

FERREIRA FILHO, Manoel Gonçalves. A disciplina constitucional das crises econômico-financeiras. Revista de Informação Legislativa, n. 108, p. 33-48, 1990.

GOODHART, Charles et al. Financial regulation: why, how and where now?. Routledge, 1998.

ROCHA, Jean Paul Cabral Veiga da. O controle de constitucionalidade da capacidade normativa de conjuntura do Conselho Monetário Nacional e do Banco Central: o caso do Fundo Garantidor de Créditos (FGC). Revista de Direito Mercantil, n. 110, p. 111-127, 2000.

- A capacidade normativa de conjuntura no direito econômico: o déficit democrático da regulação financeira. 2004. Tese (Doutorado) - Faculdade de Direito da USP, São Paulo.

SILVA, Virgílio Afonso da; ROCHA, Jean Paul Cabral Veiga da. A regulamentação do Sistema Financeiro Nacional: o art. 192 e o mito da lei complementar única. Revista de Direito Mercantil, n. 127, 2002, p. 79-92. 
538 : LEGITIMIDADE E GOVERNABILIDADE NA REGULAÇÃO DO SISTEMA FINANCEIRO

WALD, Arnoldo. A evolução do direito monetário na jurisprudência do Supremo Tribunal Federal. Revista de Direito Público da Economia, n. 18, p. 9-32, 2007.

\section{Ademir Antonio Pereira Júnior}

Alameda Jaú, 150, ap. 141
São Paulo - SP - Brasil
ademir.pereiralausp.br

BACHAREL EM DIREITO PELA FACULDADE DE DIREITO DA USP 